\title{
Why a Coffee Carafe Should Not Be Used in Cryogenic Applications
}

\author{
Philip Bennewirtz ${ }^{1 *}$ and Michal Meissner ${ }^{2}$ \\ ${ }^{1} \mathrm{KGW}$-Isotherm GmbH, 76185 Karlsruhe, Germany \\ ${ }^{2}$ FEI Company, 62700 Brno, Czech Republic \\ *p.bennewirtz@kgw-isotherm.de
}

\begin{abstract}
Proper procedures for various types of liquid nitrogen Dewars are described. To ensure the safety of employees, only components made for cryogenic applications should be used. The functionality and condition of these components should be regularly monitored. Damaged components must be replaced immediately. None of the Dewar manufacturers or electron microscope manufacturers can guarantee the personal safety and proper functionality of their devices if coffee carafes or consumer beverage flasks are used or if appropriate Dewars are used incorrectly.
\end{abstract}

\section{Introduction}

On the Internet we recently become aware of an article [1] in which coffee carafes were touted as a cheap and safe alternative to store liquid gases instead of conventional Dewar flasks. Because that article points out the "improvement of workplace safety" in the article title, we would like to outline a few important details that one should consider when choosing or buying a cryogenic vessel.

\section{Glass Liquid Nitrogen Vessels}

Coffee servers have the same basic functionality as Dewar flasks. They isolate the inserted liquid from the ambient temperature as long and as well as possible to maintain a stable temperature. Coffee carafes are produced, as the name suggests, for coffee, tea, or other hot or cold beverages. The materials used in the production of a coffeepot must be suitable for their use, a temperature range from $-20^{\circ} \mathrm{C}$ to $+100^{\circ} \mathrm{C}$. A Dewar flask for laboratory use must resist the temperatures of extremely hot fluids up to $+200^{\circ} \mathrm{C}$ as well as extremely cold fluids such as liquid nitrogen, as cold as $-196^{\circ} \mathrm{C}$. Dewar flasks dedicated for cryogenic applications are manufactured according to the accepted standards, for example, German DIN standard 12492, US ASTM E1379-90, or in the near future DIN EN ISO 16496. Such documents are setting high standards in the quality of materials and their processing. Unlike a coffee carafe, the specified minimum wall thickness for a Dewar flask must be precisely adhered to because of the high thermal loads. In addition, all Dewar vessels should be pressure-calculated and made from high-quality materials like borosilicate 3.3 glass according to DIN/ISO 3585, which is a typical material used for Dewar manufacturing (Figure 1).

In the case that a coffee carafe is made of glass, they usually use the so-called soft glass, that is, glass with a high thermal expansion coefficient. Similar to metals, different glass types should be used depending on the expected application field.

\section{Stainless Steel Liquid Nitrogen Vessels}

Besides vacuum-insulated glass Dewar flasks, there are also vacuum-insulated cryogenic vessels made of stainless

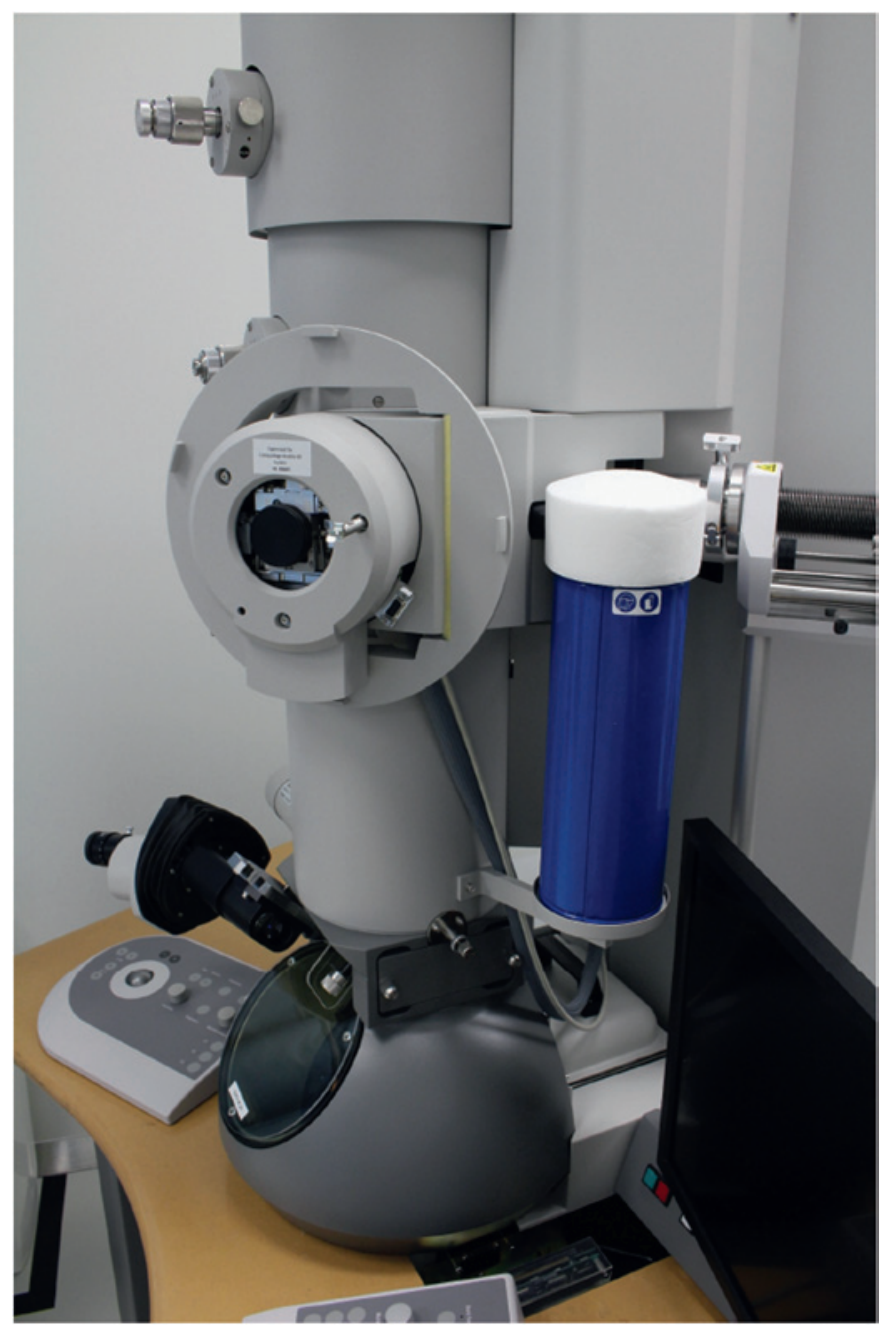

Figure 1: Cryogenic $L_{2}$ Dewar. A Dewar dedicated for cryogenic applications and manufactured from high-quality materials according to the relevant standards is recommended for use with transmission electron microscopes. Note the polystyrene cap that was placed on the top of the Dewar flask.

steel or aluminium, common in the cryogenics industry. In Europe, these flasks or containers have to be manufactured according to the "Directive on Pressure equipment 97/23/EG" or be manufactured according to the $\mathrm{AD}$ data sheets (AD data sheets are Codes of Practice on Pressure Vessels). For the manufacture of these flasks or containers, only appropriate standard materials, designated for use in this extreme temperature range, can be used. Therefore, proper attention should be paid when choosing the equipment for any cryogenic application. 


\section{Incomparable...}

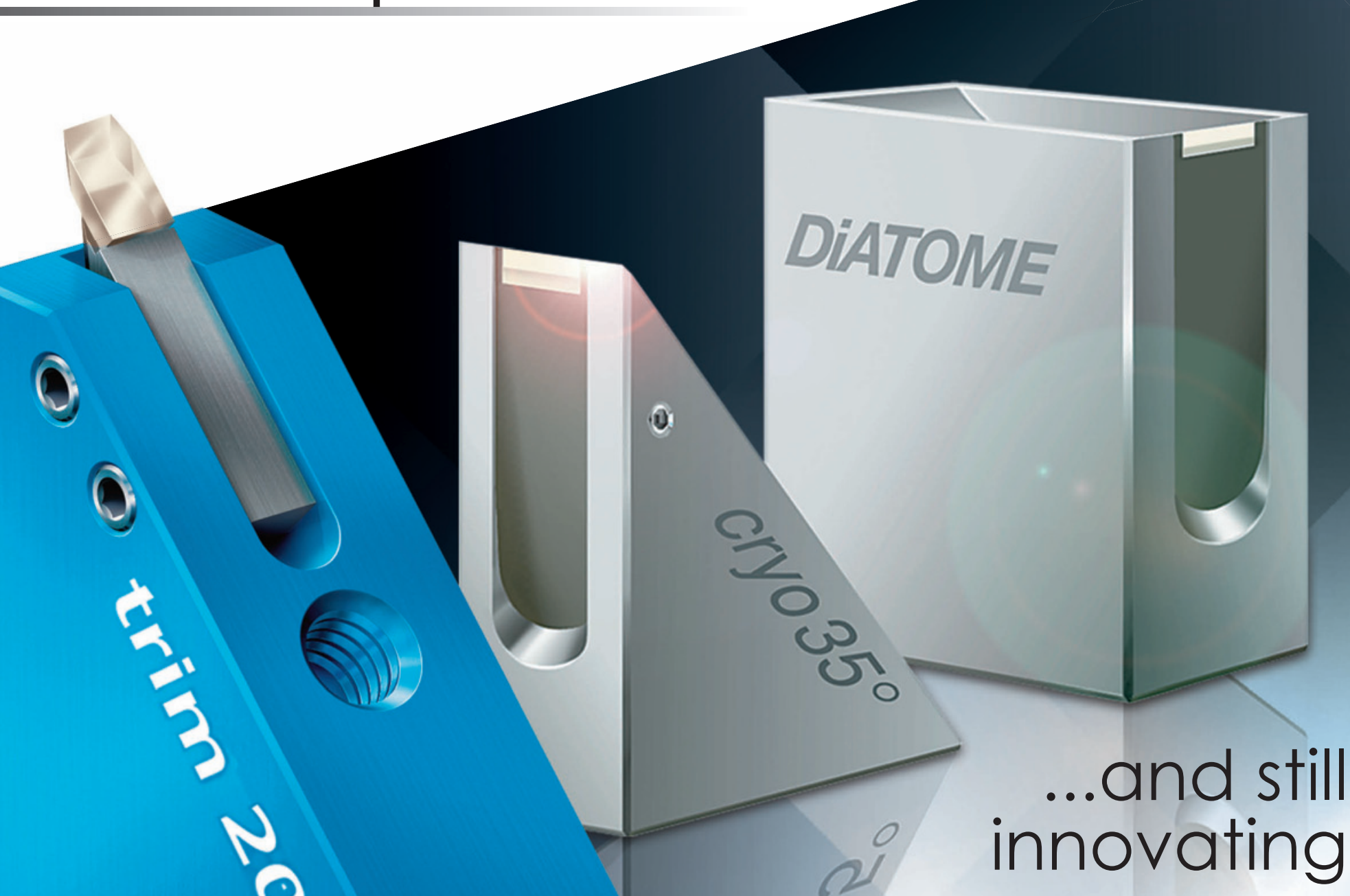

\section{DIATOME diamond knives}

ultra $45^{\circ} \cdot$ cryo $\cdot$ histo ultra $35^{\circ}$ - histo jumbo cryo immuno • ultra sonic ultra AFM \& cryo AFM trimtool 20 trimtool 45 trimtool 90

Over 40 years of development, manufacturing, and customer service

\section{DIATOME U.S.}

P.O. Box $550 \bullet 1560$ Industry Rd. • Hatfield, Pa 19440 Tel: (215) 412-8390 • Fax: (215) 412-8450 email: sgkcck@aol.com•www.emsdiasum.com
Free customer service

Sectioning tests with biological and material research specimens of all kinds. We send you the sections along with the surfaced sample, a report on the results obtained and a recommendation of a suitable knife. Complete discretion when working with proprietary samples.

Re-sharpening and reworking service

A re-sharpened Diatome diamond knife demonstrates the same high quality as a new knife. Even knives purchased in previous years can continue to be re-sharpened. The knives can be reworked into another type of knife for no extra charge, e.g. ultra to cryo or $45^{\circ}$ to $35^{\circ}$.

\section{Exchange service}

Whenever you exchange a knife we offer you a new DiATOME knife at an advantageous price.

\section{trimtool 90}

Many requests from customers doing FIB cutting of biological and technical sample blocks have motivated us to relaunch the trim 90 blade:

Please contact us for more information

DiATOME manip

Our new tool for an easy handling and mounting of section ribbons!
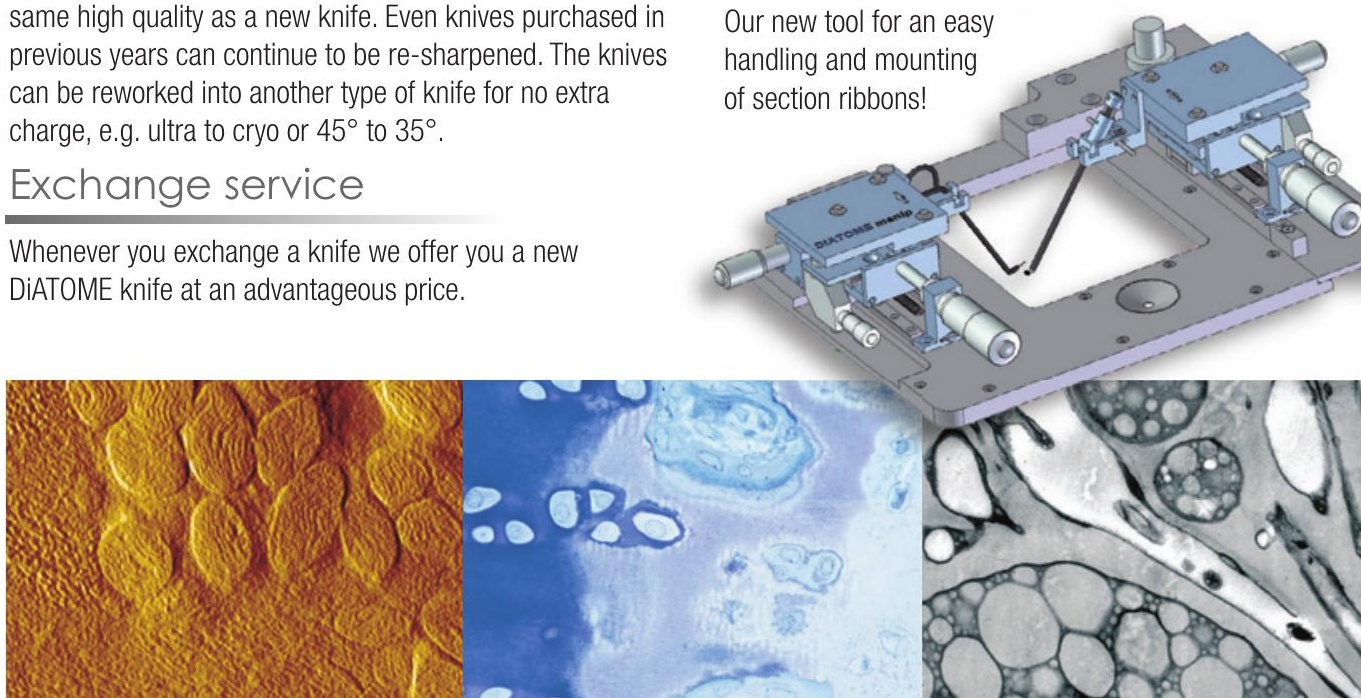
On the other hand, a coffee carafe can also be produced of stainless steel. When buying a stainless steel coffee carafe, the quality of the stainless steel is not apparent to the customer. Therefore, the user has no knowledge about whether or how long the material of the carafe made of stainless steel will withstand the thermal stresses that occur during filling with liquid nitrogen. Inappropriate types of steel can become brittle at low temperatures, which can lead to the destruction of the vessel.

\section{Surface Damage and Its Consequences}

Damage, such as surface scratches on a Dewar flask or a coffee carafe with vacuum insulation, can lead to the implosion of the flask when exposed to the extreme thermal stress experienced when filling the vessel with $\mathrm{LN}_{2}$. If an implosion occurs, the liquefied gas and the broken pieces remain within the protective casing evaporating the liquid gas. It is quite important when tightening the lid of the $\mathrm{LN}_{2}$ container that it not be fixed or have ice on top, otherwise any overpressure might not be released fast enough. This could lead to an explosion of the flask or coffeepot, which could cause serious injuries or damage. In the article [1] you can find that there is a fixed connection between the carafe and the lid through icing. If implosion, takes place, pressure will not be released efficiently, which could lead to an explosion.

If icing cannot be prevented through the testing procedure, we recommend installation of a small fan, like the type used in computer housings. The fan would blow away the humidity and prevent the lid from icing (Figure 2a).

A glass Dewar flask manufactured according to DIN 12492 or ASTM E1379-90 has an expected lifetime of at least ten years when handled properly. This statement can be made

(a)
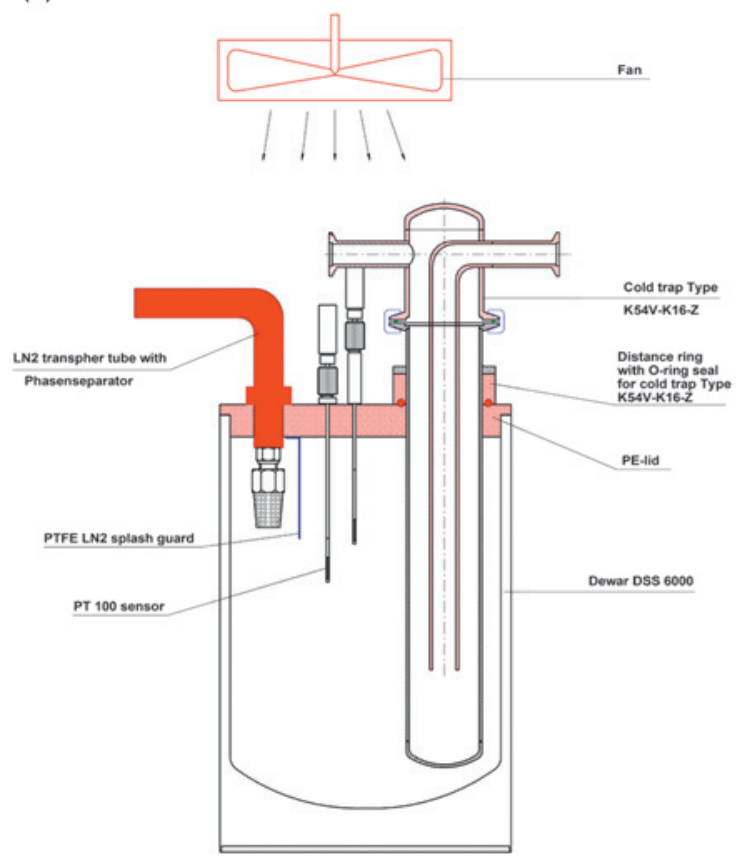

(b)

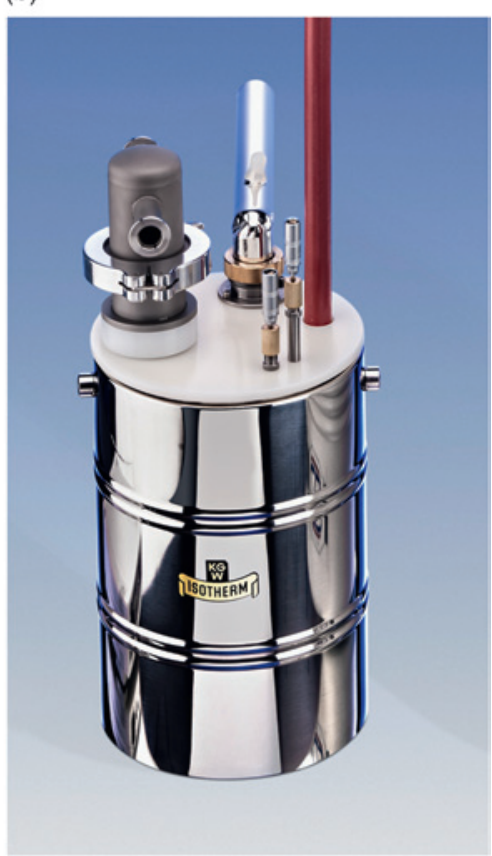

Figure 2: (a) Schematic of a Dewar with a cold trap and fan to prevent icing of the lid. (b) A gas outlet tube (projecting toward the back of the photo). because of the high standards used for the material and its manufacture when it is to be used in vacuum and cryogenic applications.

Dewar flasks made of stainless steel have a higher mechanical strength compared to the glass Dewar flasks. The disadvantage compared to a glass Dewar is the higher thermal conductivity of the stainless steel flasks. However, both materials meet necessary standards for safe use when handled properly.

Surface damage may occur in a metal Dewar or coffee carafe. This can be caused by mechanical stress or corrosion, allowing a crack or a leak to develop in the vacuum space. The liquid nitrogen would be then sucked into the vacuum and come into contact with the warm outer wall of the flask. This would lead to a rapid evaporation during the phase change from liquid to gas, and the volume would increase by about 700 times. This leads to a rapidly increasing pressure inside the vacuum space. The increased pressure cannot be compensated by exhausting gas through the leak, and the valve may become damaged by the extreme overpressure. In order to reduce this overpressure, only Dewar flasks made of stainless steel in accordance to the "Directive on Pressure Equipment - 97/23/EC" have a combined vacuum/ overpressure valve placed at the vacuum chamber (Figure $2 b$ ). A coffee carafe, for example, does not have this combined vacuum and pressure relief valve. Penetration of $\mathrm{LN}_{2}$ into the vacuum chamber of a carafe may lead to an explosion in extreme cases.

Such destructive explosions cannot occur when using a glass Dewar correctly. Only implosions happen; the glass splinters collapse and are not ejected with high speed. Because there is a protective casing out of metal or aluminium, the shards of glass as well as the liquid nitrogen will come to rest inside the casing.

Only a tightly closed Dewar flask can lead to an explosion. Therefore, it is standard for Dewar flasks to be operated only with loose plugs when they are filled with cryogenic liquids, such as $\mathrm{LN}_{2}$ or cold $\mathrm{CO}_{2}$. When the pressure rises from gassing liquids in a tightly closed Dewar, they cannot exhaust. The increase in pressure would inevitably lead to an explosion. If a lid is required for a specific application of a Dewar vessel, the lid must be provided with an exhaust hole or some other suitable opening so the resulting gas can escape.

\section{Reducing Risks}

Safety is of prime concern for all laboratory workers. To avoid workplace risks, users of $\mathrm{LN}_{2}$ containers should strictly adhere to the following: (a) respectallcountry-specificrequirements for handling liquefied gases, (b) use 
only devices and components designed for cryogenic applications, (c) follow the operating instructions of the respective manufacturer, (d) use appropriate personal protective equipment, (e) obtain regular training and instructions in the handling of the equipment and the gases, and (f) inspect the surface of the Dewar every time before using. There should be no scratches, no burst of glass, and no residues of any material on the glass. If a visual check finds one of the above-mentioned defects, the Dewar flask should be removed from service directly. The flask could implode when the user fills it with $\mathrm{LN}_{2}$ because of the high thermal stress experienced when the glass or metal surface cools down within seconds.

In the article by Dr. Barlow [1] the following incident involving a glass Dewar with a completely iced and fixed lid was described: "When a user gave the Dewar a slight twist to break the icicle, the twist instead broke the LN-filled glass liner. When the LN hit the metal walls of the Dewar, it vaporized. The rapid expansion of $L N$ within the narrow bore of the Dewar, coupled with the fragmentation of the glass into minute pieces, led to an upward explosion of glass fragments that the user described as a "stream of confetti shooting to the ceiling. For weeks afterward, we found glass "confetti" in and around crevices in the TEM room. Discussions with our service engineers revealed that similar breaks in glass-lined Dewars have occurred in labs around the world."
For us, authors of the present article, it is hard to say what led to this explosion. We can only guess what could lead to such an incident. One obvious aspect is that the icicle closed the Dewar so completely that there was overpressure inside the Dewar. By twisting the icicle to break it away from the Dewar, the user may have brought too much tension to the glass so that it broke seconds before he could divide the Dewar from the iced lid. So the $\mathrm{LN}_{2}$ headed up inside the casing of the broken Dewar, pressure rose up rapidly, and then the glass parts and the gas flew out the Dewar's casing.

\section{Conclusion}

To prevent dangerous situations when using $\mathrm{LN}_{2}$ Dewars, we recommend that users stick to the handling procedures described above, especially the following: meet operationspecific and country-specific requirements in handling liquefied gases, use devices and components designed for cryogenic applications, follow all operating instructions, wear personal protective equipment, and perform regular training in the handling of the equipment and the gases. Moreover, when a lid is used, the lid must be loose on top so that pressure can be released. Otherwise a $5 \mathrm{~mm}$ hole should be drilled in the lid to release the pressure continuously, or a gas outlet pipe should be installed.

\section{References}

[1] S Barlow, Microscopy Today 22(1) (2014) 46-48.

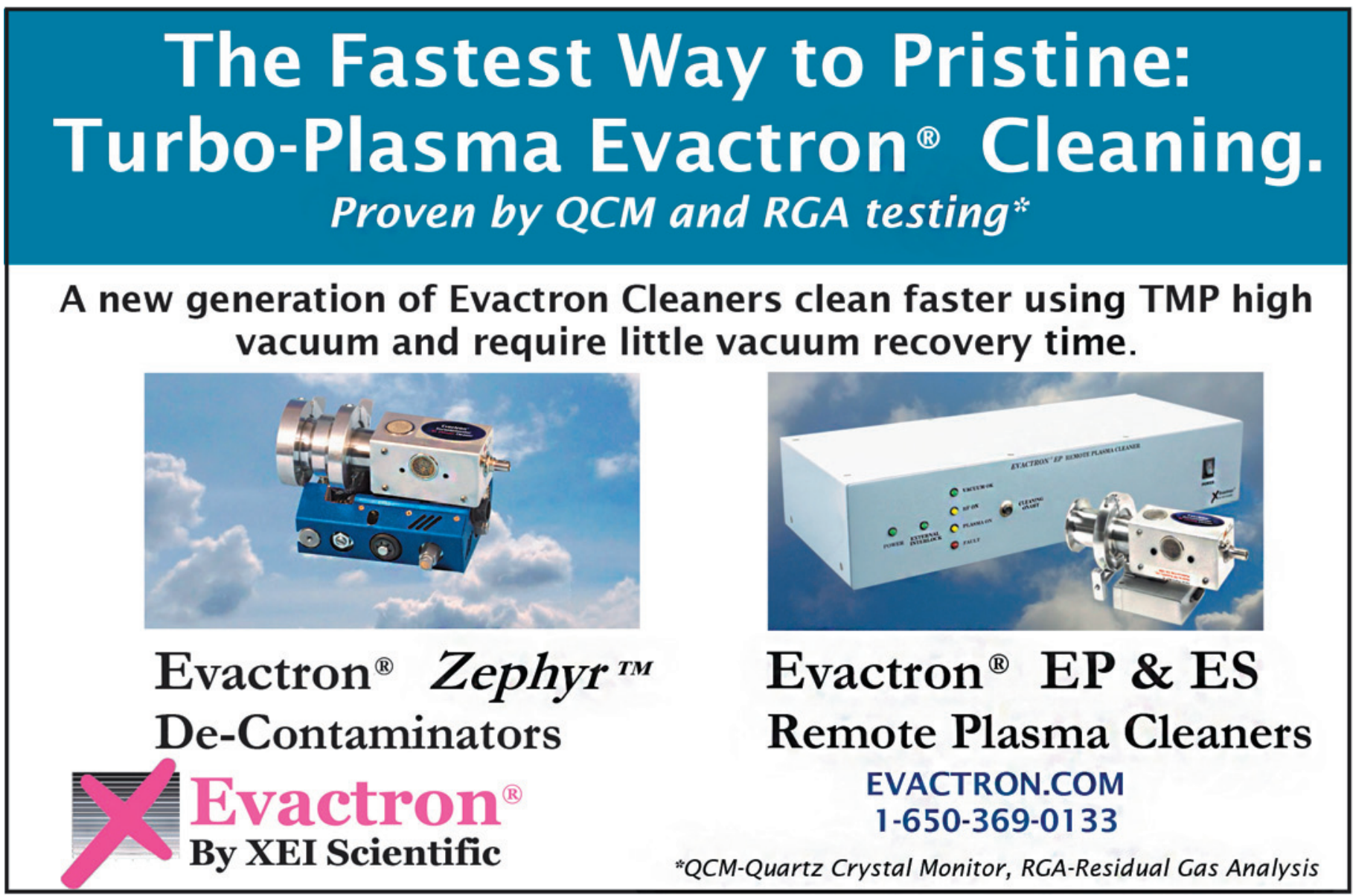

